\title{
28 Research Soure \\ Health-related Quality of Life Among Cervical Cancer Patients at Kenyatta National Hospital
}

\author{
Mehreen Shajahan Ahamed \\ United States International University \\ Amsalu Degu ( $\nabla$ amsaludegu@yahoo.com ) \\ United States International University https://orcid.org/0000-0002-6562-0548
}

\section{Research}

Keywords: Cervical Cancer, Health-Related Quality of life, Kenyatta National Hospital

Posted Date: August 30th, 2021

DOI: https://doi.org/10.21203/rs.3.rs-841174/v1

License: (c) (i) This work is licensed under a Creative Commons Attribution 4.0 International License. Read Full License 


\section{Abstract}

Background: A previous systematic review showed that health-related quality of life (HRQoL) was adversely affected during treatment of cervical cancer, with a worsening global score. However, there was a lack of data in the study setting. Therefore, this study aimed to determine the HRQoL of cervical cancer patients at Kenyatta National Hospital.

Methods: A cross-sectional design of the study was employed among cervical cancer patients. All eligible cervical cancer patients during the study period were included in the study. Hence, a consecutive sample of 103 cervical cancer patients was involved in the study. Following consent, study participants were interviewed using The European Organization for Research and Treatment of Cancer Quality-of-Life Questionnaire 30 (EORTC QLQ-30) and Cervical Cancer Module CX24 (EORTC QLQ-CX24). The clinical characteristics and treatment regimens were collected by reviewing the medical records. Interpretation and linear transformation of the raw score of health-related quality of life were conducted as per EORTC QLQ 30 and EORTC QLQ-CX24 Scoring Manual. The data were entered and analyzed using the Statistical Package for Social Sciences version 20.0 software. Frequency tables mean, percentage, and figures were used to represent the data. Univariate and multivariate binary logistic regression analysis was employed to investigate the associated factors of health-related quality of life. A p-value of $\leq 0.05$ was considered statistically significant.

Results: The mean age of the participant population was found to be $55.8 \pm 5.6$ years. Most of the study participants had stage III cervical cancer (56.3\%) and without comorbidities (65\%). The mean score of the global health status was 41.99. The physical functioning, cognitive functioning, and financial difficulties mean scores were 71.6, 73.3, and 93.5, respectively. Under the symptom scale, nausea and vomiting, pain, and appetite loss had mean scores of $70.1,67.2$, and 66.0 , respectively. The overall quality of life data showed $69 \%$ of study participants had poor quality of life while $31 \%$ of study participants had good quality of life. Patients with early-stage disease (stage I and II) were 7.3 times (AOR $=7.3,95 \% \mathrm{Cl}=2.4-$ $21.7, p=0.000)$ more likely to have a good quality of life than patients with advanced-stage disease. Patients with no comorbidities were 3.1 times $(\mathrm{COR}=3.1,95 \% \mathrm{Cl}=1.1-9.1, \mathrm{p}=0.037)$ more likely to have a good quality of life than patients with comorbidities.

Conclusions: The overall health-related quality of life among cervical cancer patients was poor in the study setting. Advanced stage of disease and presence of comorbidities were the significant predictors of poor quality of life.

\section{Background}

Cancer is the central and most cardinal cause of morbidity and mortality worldwide. According to the World Health Organization (WHO) 2018 report, cancer was the second leading cause of death, causing an estimated 9.6 million deaths (1). The Catalan Institute of Oncology and the International Agency for Research in Cancer Information Centre on Human Papilloma Virus (HPV) and cancer approximate that 
every year 5250 females are diagnosed with cervical cancer, and 3286 dies from the condition (2). Global Cancer Incidence, Mortality and Prevalence databases released in 2018 stated that ten years later, cervical cancer persists in being a major health issue, graded as the fourth most prevalent type of cancer and a significant cause of mortality among women (3).

In underdeveloped nations, cervical cancer is the most prevalent type of cancer. Persistent HPV infections are the root cause of most cervical cancer (2) and are responsible for $99.7 \%$ of cervical cancer cases (4). The largest preponderance of HPV infections is seen in the Sub-Saharan Africa female population (5). According to a WHO report, 33 per 100,000 women aged between 15 and 44 in Kenya have cervical cancer, and 22 per 100,000 dies from the condition (1).

The preponderance of cervical cancer in Kenya can be imputed to numerous factors, but most importantly, the limited access to screening and prevention practices (4) and decreased immunity due to the significant prevalence of HIV infections (6). The limited access to screening and prevention can further notably be attributed to low education levels, a mediocre health system, and a general lack of awareness among Kenyan women (7).

Health-related Quality of Life is a concept that includes various aspects of well-being, encompassing an individual's physical, emotional, mental, and social functioning (8). The HRQoL can be attributed to the success or failure of the treatment and the type of treatment utilized to manage the patient (9). On that account, it is an effective tool for gauging the standard of therapy used in cervical cancer and looking at areas that can be improved in the prevention and management to improve the patient's overall prognosis.

A previous systematic review showed that HRQoL was adversely affected during treatment of cervical cancer with a worsening global score but improved 3-6 months after treatment. Besides, the review also reported that the symptoms scale of quality of life remained worse for an extended period after curative treatment of early and locally advanced stages of cervical cancer (10). The quality of life in cervical cancer patients may be predisposed to copious factors, most of which either pertain to cancer itself or the treatment modalities applied. These may include the stage of the disease, time of diagnosis, and the category of treatment. Nevertheless, a few independent factors may also come into play that may impact quality of life and encompass socio-demographic characteristics such as age, education levels, occupation, area of residence, and income (11).

Studies on gynecological cancer patients have shown that early stages (stages I and II) were associated with a more improved quality of life as compared to advanced stages (stages III and IV) (12). Besides, another study also identified that advanced stage patients experienced more issues with aspects of nausea and vomiting, loss of appetite, and issues of financial nature. Regarding therapeutic modalities utilized, patients who underwent surgery observed better outcomes and overall quality of life than patients who underwent chemotherapy and radiotherapy (11). 
Despite few studies conducted, the association between specific treatment modalities and HRQoL has not been well established (13-15). Therefore, this study aimed to determine the HRQoL of cervical cancer patients at Kenyatta National Hospital.

\section{Methods}

\section{Study design, setting, and period}

A cross-sectional design of the study was employed to assess HRQoL among cervical cancer patients at the Cancer Treatment Center of Kenyatta National Hospital. The hospital is a teaching and referral hospital founded in 1901, located in Nairobi, Kenya, on Hospital Road. The hospital has a capacity of 1800 beds and provides care and management to cancer patients. The study was conducted from March 2021 to April 2021.

\section{Target population}

The target population comprised of female patients with cervical cancer who were receiving therapy at the Cancer Treatment Center of Kenyatta National Hospital.

\section{Eligibility criteria}

\section{Inclusion criteria}

- Adult female patients (18 years and above) with a confirmed diagnosis of cervical cancer

- Patients undergoing therapy for cervical cancer or have completed at least one form of therapy

- Conscious patients who can talk during the data collection

- Patients who were willing to participate in the study.

- Patients with complete medical records of their treatment regimen

\section{Exclusion criteria}

Patients who did not consent, seriously ill, and had incomplete medical records of treatment regimens were excluded from the study.

\section{Sample size determination}

All eligible cervical cancer patients who were on treatment during the study period were included in the study. Hence, a consecutive sample of 103 cervical cancer patients was involved in the study. 


\section{Research instruments}

The first section of the data collection instrument comprised of the consent form, socio-demographics, clinical characteristics, and treatment regimens. The second section of the instrument consisted of EORTC QLQ-C30 (16) and EORTC QLQ-X24 to assess the HRQoL of cervical cancer patients (17).

\section{Pretesting}

A pretest study was conducted in $10 \%$ of the sample population by the principal investigator. The data from this study were analyzed and used to establish imperative rectifications and modifications on the questionnaires before the actual period of data collection.

\section{Data collection techniques}

The principal investigator and research assistants (two Oncology Nurses) were involved in the data collection. Appropriate training was given to the data collectors by the investigators before the commencement of the actual study. During each day of the data collection, the study participants were given a brief description of the objective of the study. Then, the patients were requested to sign a written consent to declare their participation in the study. The socio-demographics, clinical characteristics and treatment regimens were collected by reviewing the medical records of the patients. The quality of life data was collecting by interviewing the patients in the private rooms in the hospital. Interpretation and linear transformation of the raw score of health-related quality of life were conducted as per EORTC QLQ 30 (16) and EORTC QLQ-CX24 Scoring Manual (17).

\section{Study variables}

\section{Dependent variables}

- Health-related quality of life

\section{Independent variables}

- Sociodemographic variables such as age, marital status, level of education, area of residence, smoking, drinking, income, and occupation.

- Patient variables such as treatment modalities used, stage of cancer, time of diagnosis, and types and number of comorbid conditions present.

\section{Data analysis}


The raw score of quality of life data was entered in Micosoft excel and transformed to a scale range of 0100 as per the standard scoring procedure of EORTC QLQ 30 and EORTC QLQ-CX24 Scoring Manual.

Then the transformed data of quality of life and other sociodemographic and clinical characteristics data were entered and analyzed using the Statistical Package for Social Sciences (SPSS) version 20.0 software. Frequency tables, mean, percentage, and figures were used to represent the collected data. Univariate and multivariate binary logistic regression analysis was employed to investigate the associated factors of health-related quality of life. A p-value of $\leq 0.05$ was considered statistically significant.

\section{Operational definition of terms}

Good health-related quality of life: A high mean score $(\geq 60)$ on the functional scale and a low mean score $(\leq 60)$ on the symptom scale of the European Organization for Research and Treatment of Cancer module/ Cervical cancer module questionnaire.

Poor health-related quality of life: Represented by a low mean score $(\leq 60)$ on the functional scale and a high mean score $(\geq 60)$ on the symptom scale of the European Organization for Research and Treatment of Cancer module/ Cervical cancer module questionnaire.

\section{Results}

\section{Sociodemographic characteristics of the study participants}

This study was conducted on 103 cervical cancer patients. The study participants' mean age was $55.8 \pm$ 5.6 years, and most of the patients were principally under the age of 60 years $(78,75.7 \%)$. Out of the total study population, 78 (75.7\%) participants were married, and 74 (71.8\%) participants were from Nairobi county. Fifty-one (49.5\%) participants had been through secondary education, and only $2(1.9 \%)$ were illiterate. The majority $(79,76.7 \%)$ of the study participants were unemployed. All the included $(100 \%)$ participants did not smoke, and 96 (93.2\%) did not drink alcohol (Table 1).

\section{Table 1: Sociodemographic characteristics of the study participants}




\begin{tabular}{|lll|}
\hline Variables & Frequency & Percent \\
\hline Age (years) & & \\
\hline$<60$ years & 78 & 75.7 \\
\hline$\geq 60$ years & 25 & 24.3 \\
\hline Marital status & & \\
\hline Single & 25 & 24.3 \\
\hline Married & 78 & 75.7 \\
County of residence & & \\
Nairobi & 74 & 71.8 \\
Meru & 11 & 10.7 \\
Kiambu & 6 & 5.8 \\
Mombasa & 2 & 1.9 \\
Kitui & 5 & 4.9 \\
Laikipia & 4 & 3.9 \\
\hline Murang'a & 1 & 1 \\
\hline Level of education & & 100 \\
\hline Illiterate & 2 & 4.9 \\
\hline Primary & 49 & 49.6 \\
\hline Secondary & 51 & \\
\hline Diploma & 1 & \\
\hline Occupation & & \\
Unemployed & 79 & \\
Employed & 24 & \\
Smoking & & \\
Smoke & & \\
Do not smoke & & \\
Drinking & & \\
Drink alcohol & & \\
\hline Do not drink alcohol & 96.3 \\
\hline
\end{tabular}




\section{Clinical characteristics and treatment regimens of the study participants}

As shown in Fig.1, 68 (66\%) study participants had an advanced-stage disease while only 35 (34\%) participants had early-stage disease.

This study further illustrated that most of the study participants had stage III cervical cancer $(58,56.3 \%)$, while 35 (34\%) participants had stage II cervical cancer, and only $10(9.7 \%)$ participants had stage IV cervical cancer (Fig.2).

As illustrated in Fig. 3, a large population of the study participants was seen to be without comorbidities $(67,65 \%)$. In contrast, 36 (35\%) participants were observed to have comorbidities.

Among the observed comorbidities, 18 (17.5\%) participants had hypertension, while $5(4.9 \%), 6(5.8 \%), 5$ (4.9\%), and $2(1.9 \%)$ participants had a retroviral disease, asthma, diabetes, and ulcers, respectively (Fig.4).

The most common treatment modality used was a combination of weekly chemotherapy and radiotherapy using Cisplatin $40 \mathrm{mg}(88,85.4 \%)$. Chemotherapy alone using Cisplatin $40 \mathrm{mg}$ was the second most common treatment modality used $(10,9.7 \%)$, and radiotherapy alone $(3,2.9 \%)$ and surgical procedures $(2,1.9 \%)$ were the least common treatment modalities used to treat cervical cancer (Fig.5).

\section{Health-related quality of life among study participants}

The mean score of the global health status was $41.99 \pm 31.4$. The physical functioning, cognitive functioning, and financial difficulties mean scores were 71.6, 73.3, and 93.5, respectively, while the mean scores for emotional and social functioning corresponded to 49.5 and 34.1. Under symptom scale, nausea and vomiting, pain, and appetite loss had mean scores of 70.1,67.2, and 66.0, respectively, while insomnia, constipation, and diarrhea had mean scores of $27.5,19.7$, and 16.8 , respectively. Sexual worry had a mean score of 73.5, and vaginal functioning had a mean score of 51.5. Sexual enjoyment had a mean score of 16.5 , and sexual activity had a mean score of 5.2 (Table 2 ).

Table 2: Health-related quality of life functioning among cervical cancer patients 


\begin{tabular}{|c|c|c|}
\hline Questionnaire & Quality of life scale/item & Mean \pm (SD) \\
\hline \multicolumn{3}{|c|}{ Global health status / QoL } \\
\hline \multirow[t]{17}{*}{ EORTC QLQ-C30 } & Global health status & $41.99 \pm 31.4$ \\
\hline & \multicolumn{2}{|l|}{ Functional scales } \\
\hline & Physical functioning & $71.6 \pm 23.6$ \\
\hline & Role functioning & $59.9 \pm 33.6$ \\
\hline & Emotional functioning & $49.5 \pm 35.96$ \\
\hline & Cognitive functioning & $73.3 \pm 28.2$ \\
\hline & Social functioning & $34.1 \pm 39.3$ \\
\hline & \multicolumn{2}{|l|}{ Symptom scales / items } \\
\hline & Fatigue & $63.2 \pm 25.1$ \\
\hline & Nausea and vomiting & $70.1 \pm 28.9$ \\
\hline & Pain & $67.2 \pm 21.6$ \\
\hline & Dyspnoea & $44.7 \pm 39.5$ \\
\hline & Insomnia & $27.5 \pm 29.7$ \\
\hline & Appetite loss & $66.0 \pm 30.6$ \\
\hline & Constipation & $19.7 \pm 26.6$ \\
\hline & Diarrhea & $16.8 \pm 30.1$ \\
\hline & Financial difficulties & $93.5 \pm 22.4$ \\
\hline \multirow[t]{10}{*}{ EORTC QLQ-CX24 } & \multicolumn{2}{|l|}{ Symptom scales/items } \\
\hline & Symptom experience & $35.6 \pm 22.2$ \\
\hline & Body image & $40.1 \pm 39.6$ \\
\hline & Sexual/Vaginal functioning & $51.5 \pm 13.9$ \\
\hline & Lymphoedema & $35.6 \pm 36.2$ \\
\hline & Peripheral neuropathy & $43.7 \pm 33.3$ \\
\hline & Menopausal symptoms & $43.0 \pm 34.5$ \\
\hline & Sexual worry & $73.5 \pm 43.1$ \\
\hline & \multicolumn{2}{|l|}{ Functional items } \\
\hline & Sexual activity & $5.2 \pm 15.3$ \\
\hline
\end{tabular}


EORTC QLQ 30: European Organisation for Research and Treatment of Cancer quality of life questionnaire, EORTC QLQ-CX24: European Organisation for Research and Treatment of Cancer quality of life questionnaire for Cervical Cancer, QoL: Quality of life, SD: Standard deviation

The present study showed that $69 \%$ of study participants had poor overall HRQoL while $31 \%$ of study participants had good HRQoL (Fig. 6).

\section{Factors associated with predicting health-related quality of life among cervical cancer patients}

The univariate and multivariate binary logistic regression analysis revealed that patients with early-stage disease (stage I and II) were 7.3 times (AOR $=7.3,95 \% \mathrm{Cl}=2.4-21.7, \mathrm{p}=0.000)$ more likely to have a good quality of life as compared to patients with advanced-stage disease. Patients with no comorbidities present were 3.1 times $(\mathrm{COR}=3.1,95 \% \mathrm{Cl}=1.1-9.1, \mathrm{p}=0.037)$ more likely to have a good quality of life than patients with comorbidities. Nonetheless, the other parameters did not significantly affect healthrelated quality of life among cervical cancer patients (Table 3 ).

Table 3: univariate and multivariate binary logistic regression analysis of factors associated with healthrelated quality of life 


\begin{tabular}{|c|c|c|c|c|}
\hline \multirow[t]{2}{*}{ Variable } & \multicolumn{2}{|l|}{ Univariate analysis } & \multicolumn{2}{|c|}{ Multivariate analysis } \\
\hline & $\operatorname{COR}(95 \% \mathrm{Cl})$ & P-value & $\operatorname{AOR}(95 \% \mathrm{Cl})$ & P-value \\
\hline \multicolumn{5}{|l|}{ Age (in years) } \\
\hline$\geq 60$ years & 1 & & 1 & \\
\hline$<60$ years & $2.1(0.7-6.3)$ & 0.175 & $2.6(0.7-9.7)$ & 0.164 \\
\hline \multicolumn{5}{|l|}{ Stage of disease } \\
\hline Advanced stage (stage III \&IV) & 1 & & 1 & \\
\hline Early-stage (stage I and II) & $6.2(2.5-15.5)$ & $0.000^{*}$ & $7.3(2.4-21.7)$ & $0.000^{\star}$ \\
\hline \multicolumn{5}{|l|}{ Marital status } \\
\hline Married & 1 & & 1 & \\
\hline Single & $0.63(0.23-1.8)$ & 0.383 & $2.3(0.6-8.4)$ & 0.222 \\
\hline \multicolumn{5}{|l|}{ Occupation } \\
\hline Employed & 1 & & 1 & \\
\hline Unemployed & $0.87(0.3-2.3)$ & 0.784 & $0.8(0.2-2.5)$ & 0.674 \\
\hline \multicolumn{5}{|l|}{ Residence } \\
\hline Non-Nairobi resident & 1 & & 1 & \\
\hline Nairobi resident & $1.6(0.6-4.3)$ & 0.344 & $1(0.3-3.5)$ & 0.994 \\
\hline \multicolumn{5}{|l|}{ Comorbidities } \\
\hline Comorbidities present & 1 & & 1 & \\
\hline Comorbidities absent & $3.1(1.1-9.1)$ & $0.037^{\star}$ & $1.9(0.5-6.98)$ & 0.341 \\
\hline \multicolumn{5}{|l|}{ Alcohol consumption } \\
\hline Drink alcohol & 1 & & 1 & \\
\hline Does not drink alcohol & $3.2(0.7-15.4)$ & 0.140 & $2.2(0.4-12.3)$ & 0.375 \\
\hline
\end{tabular}

$\mathrm{COR}=$ Crude odds ratio, $\mathrm{AOR}=$ Adjusted odds ratio, $95 \% \mathrm{Cl}=95 \%$ confidence interval, *Statistically significant: $P$ value $\leq 0.05$

\section{Discussion}

This study showed that the mean age of the participant population was $55.8 \pm 5.6$ years, and an overriding percentage of the participants (75.7\%) were under the age of 60 years. This finding reasonably 
corresponded to other related studies by Owenga and Araya et al. (18), which showed that most patients with cervical carcinoma were aged between 25 and 54 years. This finding may be attributable to cervical cancer risk factors, such as the predominance of the exceedingly oncogenic subtypes of the HPV virus (19).

This study indicated that most participants had advanced-stage cervical cancer (66\%) compared to earlystage disease (34\%). A large population (56.3\%) had stage III cancer, while $34 \%$ had stage II cancer and $9.7 \%$ had stage IV disease. Similary, a previous study also reported that most patients had advancedstage disease (73\%) (15). This high percentage of an advanced stage in our setting may be due to an insufficiency in awareness of early screening methods among Kenyan women. Despite achieving at least a secondary school certificate (49.5\%), the perception of high susceptibility and preponderance of cervical cancer is lacklustre (14). Therefore, this would effectuate the incapability to perceive and detect some of the early symptoms that may lead to an early diagnosis.

The majority of the study population did not have any comorbidities $(65 \%)$, whereas $35 \%$ had comorbidities, with hypertension ranking the highest (17.5\%), followed by asthma (5.8\%), HIV (4.9\%), and diabetes (4.9\%). This is in line with a study by Dos Santos et al. (20), which delineated that $48.3 \%$ of the participants did not have any comorbidities present. Contrastingly, among patients with comorbidities, hypertension (43.6\%) and diabetes mellitus (21.3\%) were the most prevalent.

The most typical treatment modality employed among cervical cancer patients was chemoradiation therapy using cisplatin $40 \mathrm{mg}(85.4 \%)$. In contrast, chemotherapy alone $(9.7 \%)$, radiation therapy $(2.9 \%)$, and surgical intervention (1.9\%) were the least utilized therapeutic options. This is contrary to a study done by Araya et al. (18), which stated that the most common treatment modality used was radiotherapy (42.3\%). Furthermore, another study by Owenga revealed that chemotherapy (10\%) and total hysterectomy $(9 \%)$ were the most common treatment as compared to chemoradiation therapy (3\%) (15).

A bulk of the study population showed positive means scores for physical functioning $(71.6 \pm 23.6)$ and cognitive functioning $(73.3 \pm 28.2)$. This conceivably could be imputable to the younger age among the participants. Role functioning had an adequately good mean score of $59.9 \pm 33.6$, whereas emotional functioning $(49.5 \pm 35.96)$ and social functioning $(34.1 \pm 39.3)$ had sufficiently poor scores. Poor emotional and social functioning was attributable to symptoms such as depression, worry, and irritability, alongside a decline in social activities. This may have been promoted by the record unemployment rates (76.7\%) among the participants, which needless to say, points to low incomes, and this highly influences emotional and social functions (21). This was contrasting in Owenga's study (15), which demonstrated positive emotional and social functionality among cervical cancer patients shielded by strong religious beliefs.

On the symptoms scale, nausea and vomiting were the most experienced symptom among the study population, with a mean score of $70.1 \pm 28.9$. Nausea and vomiting are among the most common side effects of cisplatin therapy, and therefore, it was the most probable cause of the high incidence (22). Pain (67.2 \pm 21.6$)$, appetite loss $(66 \pm 30.6)$, and fatigue (63.2 \pm 25.1$)$ were also experienced by a large 
proportion of the study participants. This was in congruence with the Araya et al study (18), which demonstrated high mean scores on pain, fatigue, and appetite loss. Financial difficulties among study participants had an exceptionally high mean score of $93.5 \pm 22.4$. This may have been a consequence of most participants being unemployed $(76.7 \%)$, which insinuates inadequate wages.

The findings indicated that sexual worry was high among participants with a mean score of $73.5 \pm 43.1$, and consequently, sexual activity was remarkably low $(5.2 \pm 15.3)$. Most patients acknowledged that they were afraid to participate in any form of sexual activity due to pain, vaginal shortness, and vaginal narrowing or were too shy to engage in talks about it. This is in agreement with the Brazilian study (20), which indicated sexual performance scores were negative among participants. Besides sexual symptoms, lymphoedema, peripheral neuropathy, and menopausal symptoms had comparably lower mean scores of $35.6 \pm 36.2,43.7 \pm 33.3$, and $43 \pm 34.5$, respectively. This is consistent with a Chinese study (11).

The global health status among study participants was low, giving a mean score of $41.99 \pm 31.4$. Correspondingly, the HRQoL among study participants was largely poor $(69 \%)$, with only $31 \%$ having good HRQoL. The poor HQoL can be attributed to negative scores of emotional functioning, social functioning, sexual functioning, financial difficulties, and some of the symptom experience. This is consistent with Araya et al., which showed a global health status score of $48.3 \pm 23.77$ (18). Participants with early-stage disease were $7.3(\mathrm{AOR}=7.3,95 \% \mathrm{Cl}=2.4-21.7, \mathrm{p}=0.000)$ times more likely to have good $\mathrm{HQoL}$ as compared to patients with advanced-stage disease. There was also a positive link between the absence of comorbidities and good $\mathrm{HQOL}(\mathrm{COR}=3.1,95 \% \mathrm{Cl}=1.1-9.1, \mathrm{p}=0.037)$ compared to patients with comorbidities present. Other factors such as age, marital status, occupation, residence, and alcohol consumption were not statistically significant predictors of HQoL among cervical cancer patients. This is unlike the study done by Owenga (15), which demonstrated a statistically significant link between age, marital status, education, and overall HRQoL.

\section{Conclusions}

The overall health-related quality of life among cervical cancer patients was poor (69\%) in our setting, with a mean score of $41.99 \pm 31.4$. Emotional, social, and sexual well-being, alongside financial difficulties and some symptoms such as nausea and vomiting, were the most prevalent factors contributing to poor quality of life. Predictors of poor quality of life that were statistically significant were discerned to be the advanced stage of the disease and presence of comorbidities. Therefore, counseling measures alongside pharmacological treatment modalities should be adequately implemented to enhance emotional and social well-being.

\section{Abbreviations}

AOR: Adjusted odds ratio 
COR: Crude odds ratio

HRQoL: Health related quality of life

EORTC QLQ-30: The European Organization for Research and Treatment of Cancer Quality-of-Life Questionnaire 30

EORTC QLQ-CX24: : The European Organization for Research and Treatment of Cancer Quality-of-Life Questionnaire Cervical Cancer Module CX24

\section{Declarations}

\section{Ethics approval and consent to participate}

Authorization to conduct the study was acquired from the Kenyatta National Hospital/University of Nairobi Ethics and Research Committee (Approval number: UP18/01/2021). Clearance to use the questionnaires was granted by the EORTC research group following an e-mail to request for them. In addition to this, the confidentiality of patient information was guaranteed and maintained as anonymous during data collection. Written informed consent was obtained from all the study participants to involve the study.

\section{Consent for publication}

Written informed consent was obtained from all the study participants to publish the study's findings with anonymity.

\section{Availability of data and material}

The datasets used and analysed during the current study are available from the corresponding author on reasonable request.

\section{Competing interests}

The authors declare that they have no conflicts of interest.

\section{Funding}

\section{There was no funding to conduct this study.}

\section{Authors' contributions}

All authors contributed to the study conception and design. Material preparation, data collection and analysis were performed by MSA and AD. The first draft of the manuscript was written by MSA, and all authors commented on previous versions of the manuscript. All authors read and approved the final manuscript. 


\section{Acknowledgments}

The authors would like to acknowledge all the oncology staff members at Kenyatta National Hospital who gave us all the assistance to collect the data and the cervical cancer patients for patiently participating in the study.

\section{References}

1. WHO. Cancer [Internet]. 2018 [cited 2020 Nov 12]. Available from: https://www.who.int/newsroom/fact-sheets/detail/cancer.

2. Bruni L, Albero G, Serrano B, Mena M, Gómez D, Muñoz JBF. Human Papillomavirus and Related Diseases Report KENYA. Barcelona, Spain; 2019 Jun.

3. Bray F, Ferlay J, Soerjomataram I, Siegel RL, Torre LA, Jemal A. Global cancer statistics 2018: GLOBOCAN estimates of incidence and mortality worldwide for 36 cancers in 185 countries. CA Cancer J Clin. 2018 Nov;68(6)(1):394-424.

4. Were C, Makumi D, Kiptui DJ, Kalebi A, Karagu A, Odhiambo A, et al. Kenya National Cancer Screening Guidelines [Internet]. 2018 [cited 2020 Oct 26]. Available from: https://www.health.go.ke/wp-content/uploads/2019/02/National-Cancer-Screening-Guidelines2018.pdf.

5. Tulay P, Serakinci N. The role of human papillomaviruses in cancer progression. J Cancer Metastasis Treat. 2016.

6. Grischke EM, Brucker SY. Cervical cancer. Medizinische Monatsschrift fur Pharmazeuten. 2019.

7. Ng'ang'a A, Nyangasi M, Nkonge NG, Gathitu E, Kibachio J, Gichangi P, et al. Predictors of cervical cancer screening among Kenyan women: Results of a nested case-control study in a nationally representative survey. BMC Public Health. 2018 Nov 7;18(Suppl 3).

8. Yin S, Njai R, Barker L, Siegel PZ, Liao Y. Summarizing health-related quality of life (HRQOL): development and testing of a one-factor model. Popul Health Metr. 2016 Dec 11;14(1):22.

9. Prasongvej P, Nanthakomon T, Jaisin K, Chanthasenanont A, Lertvutivivat S, Tanprasertkul C, et al. Quality of life in cervical cancer survivors and healthy women: Thai urban population study. Asian Pacific J Cancer Prev. 2017;18(2):385-9.

10. Wiltink LM, King M, Müller F, Sousa MS, Tang M, Pendlebury A, et al. A systematic review of the impact of contemporary treatment modalities for cervical cancer on women's self-reported healthrelated quality of life. Support Care Cancer. 2020;28(10):4627-44.

11. Thapa N, Maharjan M, Xiong Y, Jiang D, Nguyen TP, Petrini MA, et al. Impact of cervical cancer on quality of life of women in Hubei, China. Sci Rep. 2018;8(1):2-10.

12. Güngör I, Oskay U, Kocaoğlan I. Factors Affecting Quality of Life and Fatigue in Gynaecologic Cancer Patients. Int J Med Res Heal Sci. 2017;6(6):109-17. 
13. Owenga JA. Holistic Care: An Urgent Need for Cervical Cancer Patients in Kenya. Int J Eur Stud. 2019;3(1):15.

14. Abdikarim IK, Miriam W, Atieno C, Habtu M. Prevalence and Associated Factors of Cervical Cancer Screening among Somali Women in an Urban Settlement in Kenya Community \&. Public Health Nurs. 2017;3(1):1-6.

15. Owenga JA. Assessment of Health Related Quality of Life in Cervical Cancer Patients in Western Kenya. Am J Nurs Sci. 2018;7(6):325-32.

16. Aaronson NK, Ahmedzai S, Bergman B, Bullinger M, Cull A, Duez NJ, et al. The European organization for research and treatment of cancer QLQ-C30: A quality-of-life instrument for use in international clinical trials in oncology. J Natl Cancer Inst. 1993;85(5):365-76.

17. Greimel ER, Vlasic KK, Waldenstrom AC, Duric VM, Jensen PT, Singer S, et al. The European Organization for Research and Treatment of Cancer (EORTC) Qualtty-of-Life questionnaire cervical cancer module: EORTC QLQ-CX24. Cancer. 2006;107(8):1812-22.

18. Araya LT, Fenta TG, Sander B, Gebremariam GT, Gebretekle GB. Health-related quality of life and associated factors among cervical cancer patients at Tikur Anbessa specialized hospital, Addis Ababa, Ethiopia. Health Qual Life Outcomes. 2020;18(1):1-9.

19. Seppä K, Pitkäniemi J, Malila N, Hakama M. Age-related incidence of cervical cancer supports two aetiological components: A population-based register study. BJOG An Int J Obstet Gynaecol. 2016 Apr 1;123(5):772-8.

20. Dos Santos LN, Castaneda L, De Aguiar SS, Thuler LCS, Koifman RJ, Bergmann A. Health-related Quality of Life in Women with Cervical Cancer. Rev Bras Ginecol e Obstet. 2019;41(4):242-8.

21. Klügel S, Lücke C, Meta A, Schild-Suhren M, Malik E, Philipsen A, et al. Concomitant psychiatric symptoms and impaired quality of life in women with cervical cancer: A critical review. Vol. 9: International Journal of Women's Health. Dove Medical Press Ltd; 2017. pp. 795-805.

22. Astolfi L, Ghiselli S, Guaran V, Chicca M, Simoni E, Olivetto E, et al. Correlation of adverse effects of cisplatin administration in patients affected by solid tumours: A retrospective evaluation. Oncol Rep. 2013 Apr;29(4):1285-92.

\section{Figures}




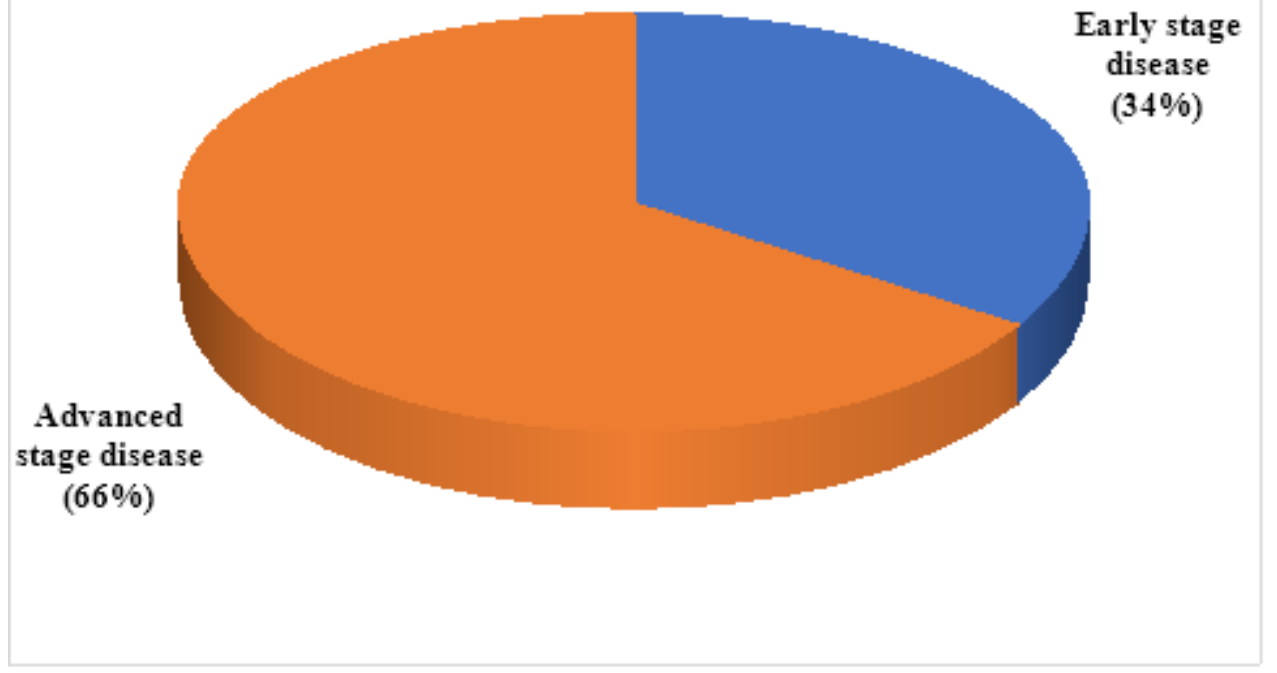

Figure 1

Staging of disease among participants

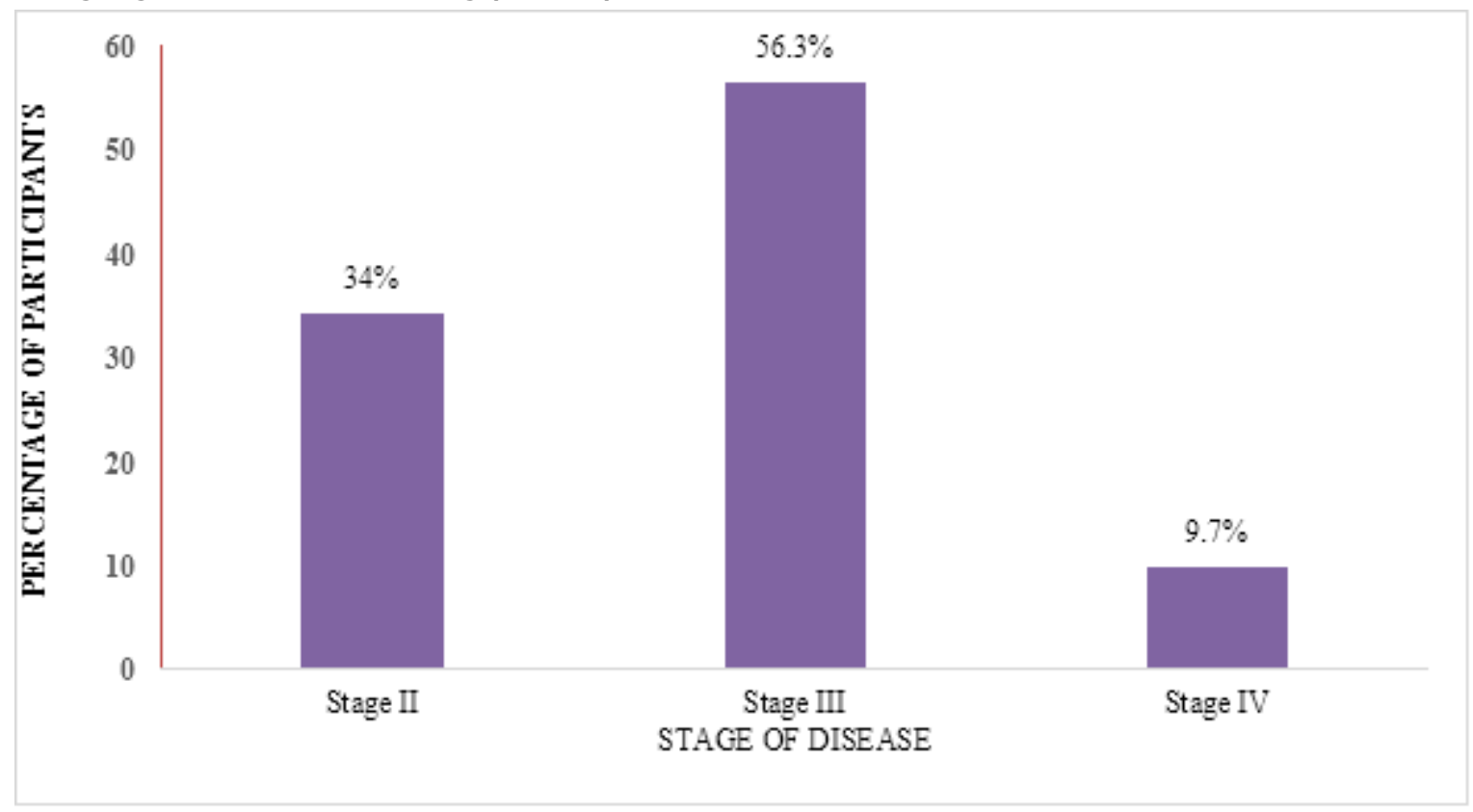

Figure 2

Stages of cervical cancer found among study participants 


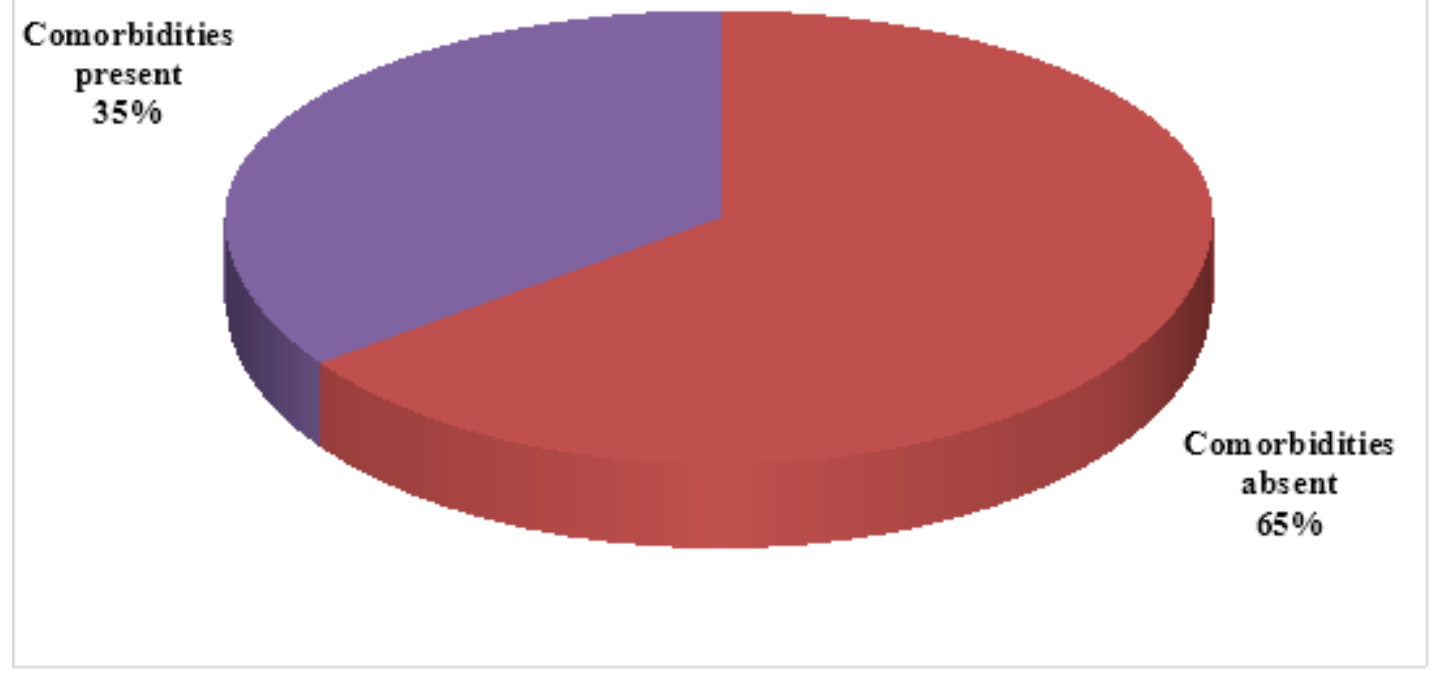

Figure 3

Presence of comorbidities among cervical cancer patients

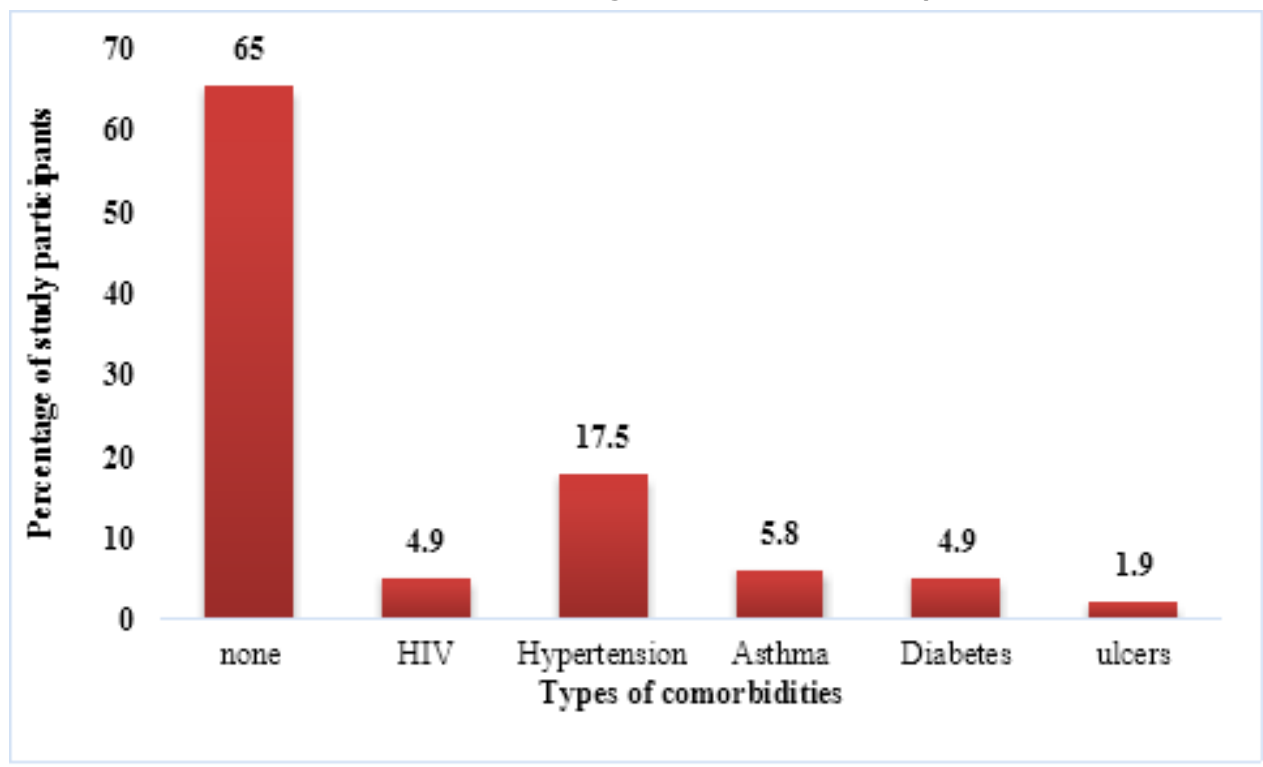

\section{Figure 4}

Types of comorbidities present among the study participants 


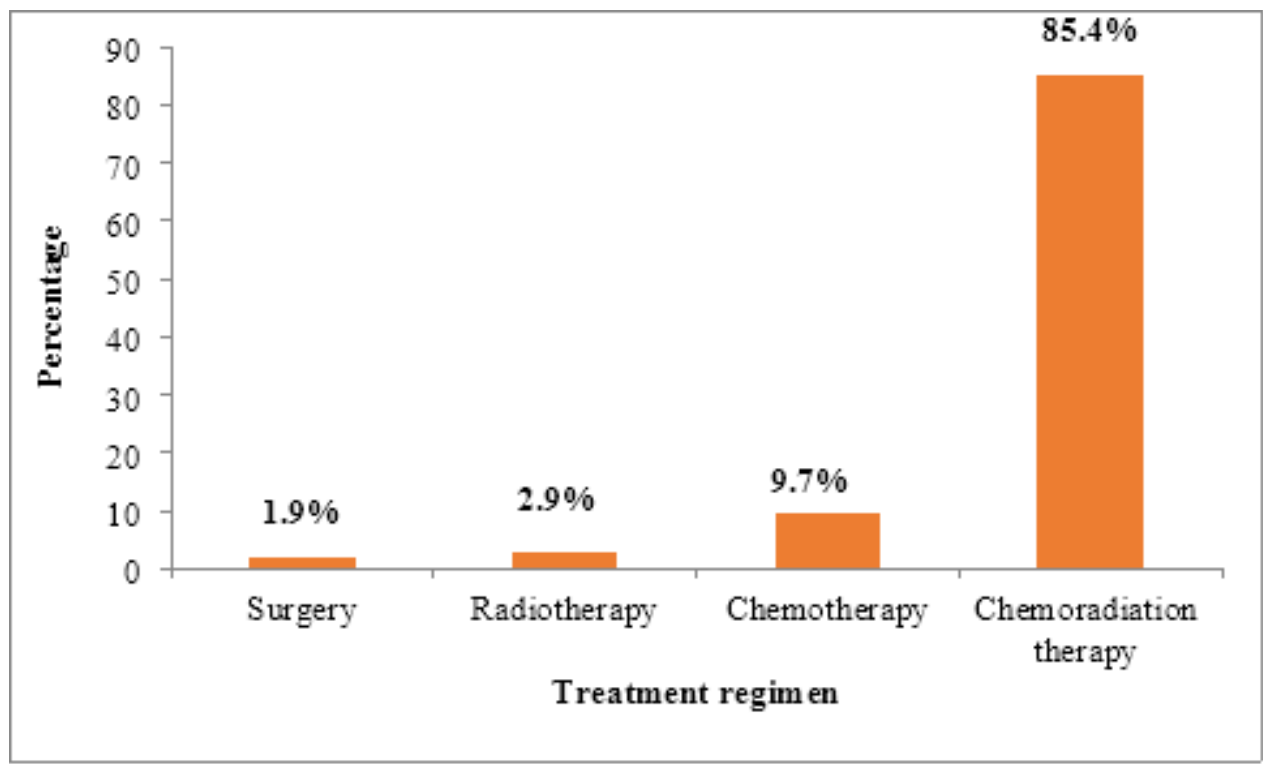

Figure 5

Treatment modalities used in cervical cancer management

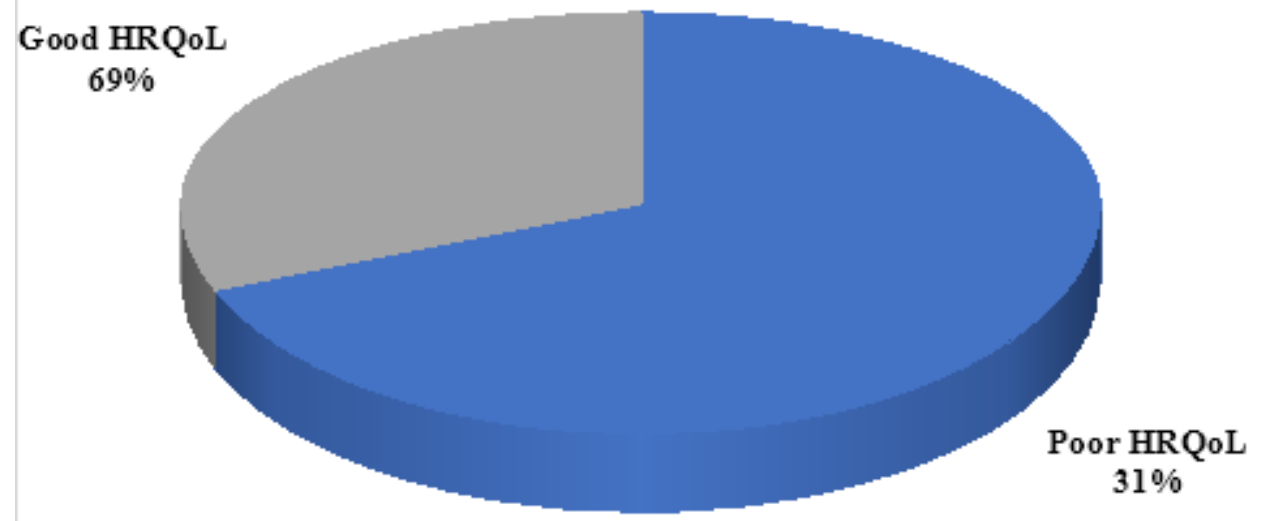

Figure 6

Overall health-related quality of life among study participants 